\title{
THE INFLUENCE OF CONTAMINATED HYDRAULIC FLUID ON THE RELATIVE VOLUME FLOW RATE AND THE WEAR OF RUBBING PARTS OF THE AVIATION PLUNGER PUMP
}

\author{
Volodymyr BRAZHENKO \\ College of Engineering, Zhejiang Normal University, Jinhua, China
}

Received 7 November 2018; accepted 23 April 2019

\begin{abstract}
Still, there is the problem of the plunger pumps failures due to pollution of the working fluid with mechanical impurities in civil aviation. The article deals with experimental research the change of relative volume flow rate of plunger pump model NP-72M which depends on the working fluid purity. In particular, the negative effect of increasing the particle size of impurities (electrocorundum about $3 \mu \mathrm{m}, 10 \mu \mathrm{m}, 20 \mu \mathrm{m}$ ) and increasing particles concentration (about 25-150 mg/L) with the constant particle size on pump operation has presented. This has manifested in increased wear of rubbing parts and reduced the relative volume flow rate. A visual inspection of the pump parts has carried out, and the most damaged areas have identified.
\end{abstract}

Keywords: plunger pump, mechanical impurities, contaminated hydraulic fluid, relative volume flow rate, wear of rubbing parts.

\section{Introduction}

A hydraulic drive is a combination of devices, with the transfer of mechanical energy and a converting the movement through the working fluid. Hydraulic drives belong to the class of closed hydraulic systems. The main components of the hydraulic drive are hydraulic motors and hydraulic pumps (or hydraulic couplings), which they are hydraulic machines. All units of the hydraulic system connect through pipelines where the working fluid moves. At present, in the world aviation, the most exploited airliners have pressure in hydraulics about $210 \mathrm{~atm}$. However, the exception to the rule is the pressure of the hydraulic system of the Airbus A320 reaches 350 atm. Thus, the main disadvantage of the hydraulic systems is the operation of the aggregates with high pressure. These devices are responsible for flight safety directly. Of course, there is a duplicate of hydraulic system on modern aircraft and its consists of several subsystems with backup power sources - torque converters. When one hydraulic system fails, the consumer continues to feed on the other with no problems. Anyway, the failure of any element can entail negative consequences. High pressure leads to increase wear of hydraulic components and contamination of the working fluid. However, this pressure maintains the operation of the aircraft's hydraulic system in normal mode.
Thus, the hydraulic system should subject to timely maintenance.

Hydraulic systems with plunger pumps of constant and variable performance widely use on airplanes. The latter type uses much more frequent and it's a paramount source of pressure. According to the analysis of aviation safety, annually, several aviation incidents had connected with a breakdown and a power reduction of a plunger pump. In most cases, the cause of failure of the pump is a contamination of the working fluid by mechanical impurities (The West-Siberian..., 2015, 2016, 2017; National bureau..., 2015).

Thus, the main purpose of the study is to determine the effect of mechanical impurities (pollution) in the working fluid on the operation of the plunger pump. Moreover, the hardness of pollution should exceed the hardness of the rubbing parts in the plunger pump. The relative volume flow rate of the plunger pump has selected for the performance indicator.

The role of these factors (discharge and suction pressure, temperature and purity of the working fluid, etc.) has not been sufficiently studied, or results have outdated and don't have an experimental basis (Kovalev, 2009; X. Wang, Lin, S. Wang, He, \& Zhang, 2016; Hong \& Doh, 2004). However, studies have conducted in recent years suggest,

${ }^{*}$ Corresponding author. E-mail: v_brazhenko@ukr.net 
that one of the main factors is the degree of purity of the working fluid, which affects the service life of the pumps (Boldyrev \& Budarova, 2016; Labunets, et al. 2010).

\section{Conducting an experiment and results of an experimental study}

Hydraulic pump NP-72MV was intended to create pressure in the main hydraulic system of the aircraft. It is a rotary-type plunger pump with an end distribution of the working fluid of the adjustable productivity. It has the operational characteristics presented in Table 1. This pump is used as a source of the working fluid pressure of the hydraulic system of the currently operating airplanes (An-72, An-74, An-32, An-140, Yak-42) and helicopters (Mi-28 and $\mathrm{Mi}-28 \mathrm{~N})$.

Table 1. The main operational characteristics of the pump NP-72MV

\begin{tabular}{|l|c|}
\hline A working pressure, $\mathrm{MPa}$ & $15.0+1.5$ \\
\hline The volume flow rate, $\mathrm{L} / \mathrm{min}$ & $25 \ldots 27.5$ \\
\hline The minimum suction pressure $\mathrm{MPa}$ & $\sim 0.17$ \\
\hline The working fluid & AMG-10 \\
\hline $\begin{array}{l}\text { The working temperature range of the } \\
\text { working fluid, }{ }^{\circ} \mathrm{C}\end{array}$ & $-60+90$ \\
\hline $\begin{array}{l}\text { Maximum number of revolutions of the } \\
\text { shaft, rev / min }\end{array}$ & 4000 \\
\hline
\end{tabular}

While investigating the resource of the pump on contaminated fluid the task wasn't to simulate the operating conditions, characterized by different dynamic and thermal conditions, pollution conditions, etc. Therefore, to study the effect of any one factor, for example, the size of particles of a pollutant on the pump operation, the bench tests conditions are the most acceptable. Bench tests allow to protect the system from an external contaminant and maintain a given concentration and size of the pollutant, the temperature of the working fluid, etc. Thus, the tests allow to exclude or minimize other types of wear of pump parts, except for abrasive.

The experimental bench was set up to study the impact of pollution on the work of the plunger pump. Figure 1 shows its simplified hydraulic scheme. The series of experiments have carried out. The experimental bench has worked as follows. From the tank 7, the contaminated fluid has entered inside the test pump 6 . The throttle 3 and the pressure sensor 2 (pressure gauge) have used to control the pressure. Safety valve 1 has used to prevent an accident. An oil flow meter 4 (PIUSI K600 / 4) and a tap 5 have used to measure the flow in the system. Test mode of the pump has selected based on the following considerations. First of all, the mode and operating conditions of the pump should comply with Table 1 . Secondly, the time of the experiment should be short but allowing the registration of instruments readings.

The pump operation has provided comparative results within 2-16 hours in a given mode using electrocorun- dum as a pollutant at a concentration of $25-150 \mathrm{mg} / \mathrm{L}$. The hardness of electrocorundum on the Mohs scale is 9 units. It exceeds the hardness of the rubbing parts in the plunger pump. The choice of the particle size of the pollutant in the range from 1 to $20 \mu \mathrm{m}$ has explained by the following considerations. The hydraulic systems of modern aircraft have equipped with fine filters. They filter out particles with a size of $10,20 \mu \mathrm{m}$ and above, depending on the type of filter elements. Thus, the probability of circulation in the hydraulic system of particles with a size from 1 to $20 \mu \mathrm{m}$ is greater than the circulation of large particles, for example, 50 or $100 \mu \mathrm{m}$. In addition, in real conditions, small particles of the pollutant are in larger quantities than big ones. Consequently, the probability of their presence in the system will also be greater.

An artificial pollutant (electrocorundum) was previously prepared according to the required dimensions. It was weighed on an analytical balance with an accuracy of 1-2 mg and add into a glass with pure working fluid AMG-10, where it was thoroughly mixed. Then the contents of the glass were poured into the tank of the system, where, by means of a mixer, for 20-30 minutes the working fluid AMG-10 was intensively mixed to create a uniform concentration of the pollutant. After that, a sample of the working fluid was taken and the installation was started.

During the experiment, the pollutant has introduced into the system usually once, before the start of the experiment. This method of contamination of the fluid does not reflect the real picture of the systematic penetration of the pollutant into the hydraulic system during operation. However, some analogy with the operating conditions can be found in this method. If we imagine that the pollutant got into the system during installation, repair or refilling with dirty working fluid. At this moment, its concentration is greatest.

The method of a single supply of pollutant to the system is more convenient than the method of multiple supply. It is not associated with conducting an experiment with different variations, it reduces the error in determining the pollutant during backfilling, etc.

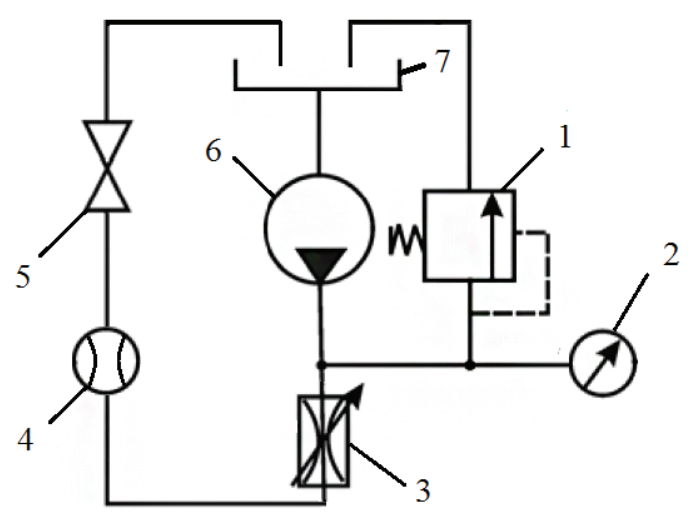

Figure 1. Simplified hydraulic diagram of the experimental stand 
Effect of pollution of operating fluids in aircraft hydraulic pumps work manifested in the reduction of the relative volume flow rate:

$$
\xi=\frac{Q^{\prime}}{Q^{\prime \prime}},
$$

where $Q^{\prime}$ та $Q^{\prime \prime}$ - respectively, the actual pump flow before and after wear at a certain fluid pressure. The value of $\xi$ decreases with increasing size (Figure 2) and concentration (Figure 3) of solid particles polluting the fluid.

If we consider the results of the study of the relative volume flow rate with different sizes of impurity particles in fluid depending on the pump operation time (Figure 4), then it should be noted that the decrease in $\xi$ of the pump can be divided into two stages. The first stage is characterized by an intense decrease in $\xi$ and significant wear of rubbing pairs to a value determined by the size and concentration of the pollutant (clearly manifested for pollution particles of $3 \mu \mathrm{m}$ and $10 \mu \mathrm{m}$ ), as well as a significant increase in the concentration of particles produced by the

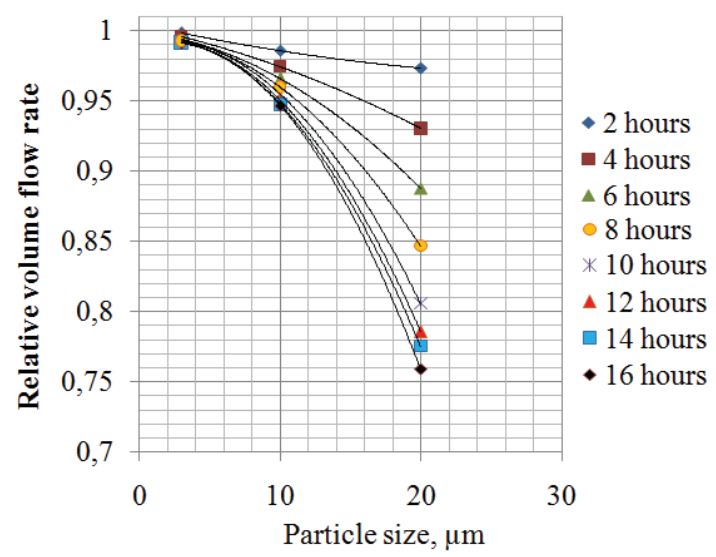

Figure 2. Nomogram of the dependence of the relative volume flow rate on the particle size of the impurity at a certain time of continuous operation and with a certain impurity concentration

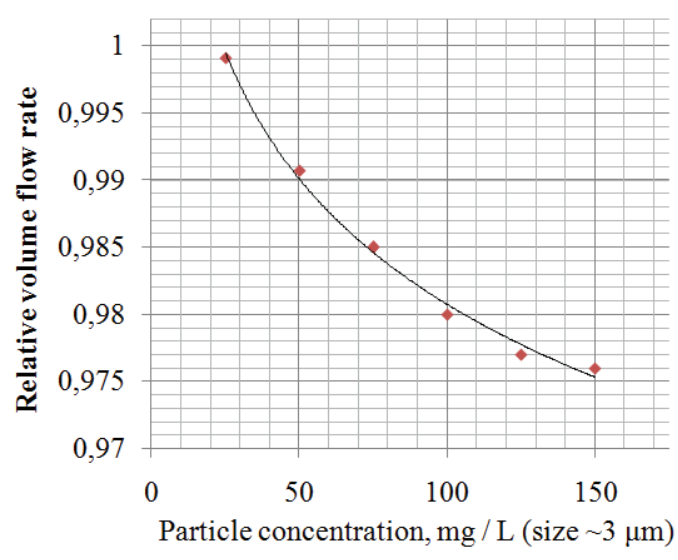

Figure 3. The plot of the dependence of the relative volume flow rate on the pump impurity particle concentration $(\sim 3 \mu \mathrm{m}$ in size) with a continuously operating pump time ( 8 hours) wear of pump parts. The second stage is characterized by a gradual decrease in $\xi$ and a slight wear of the rubbing pairs.

\section{Visual inspection of the pump after the experiment}

When inspecting rubbing parts used in the operation of pumps with a pollutant size of about $20 \mu \mathrm{m}$ in the working fluid, it was found that the working surfaces of the plunger and the cylinder block and the valve plate covered with concentric furrows, the depth of which is 1-20 $\mu \mathrm{m}$. (Figure $5 \mathrm{a}, \mathrm{b}, \mathrm{c}$ ). Depreciation of the plungers is not uniform over the entire surface. The surfaces of the pump plunger are covered with small grooves, directed both along the movement of the plunger and randomly (Figure $5 \mathrm{~d}$ ).

Figure $5 \mathrm{c}$ is the photo. It has made under a microscope. The photo has shown damage on the surface of the plunger due to impurity particles. There were the pieces of the electrocorundum material with $4-10 \mu \mathrm{m}$ in size in grooves of the plunger. The shape of pieces is the approximate hexatetrahedron.

The grooves on the plungers and cylinder blocks, matte spots of contact on the plunger skirt and traces of rolling appear due to abrasive foreign particles present in the oil circuit. Plungers with worn working side surface no longer provide sufficient cylinder sealing. This leads to an increase in pressure behind the plungers and an increase in leakages. Possible consequences: hydraulic fluid outflow in the area of the radial sealing rings of the shaft and other locations of seals. Traces of skating are appeared on the plungers in case of deposition of dirt particles in the annular grooves (if any). The impurity particles in the groove are touched with the surface of the plunger when it is rotating. As a result typical rolling tracks are formed on the plunger.

Due to the saturation of the surface of the plunger with abrasive particles, the wear of the surface of the cylinder block is greater than the plunger. The different state of the

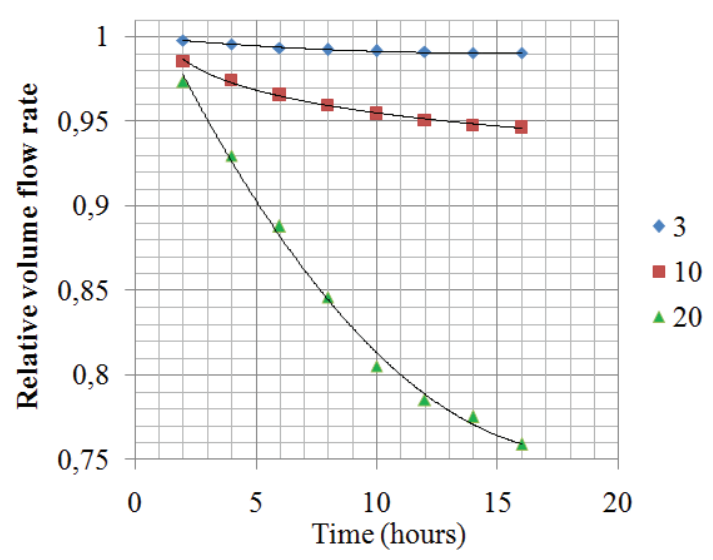

Figure 4 . The plots of the change of the relative volume flow rate with the different pump impurity particle size 

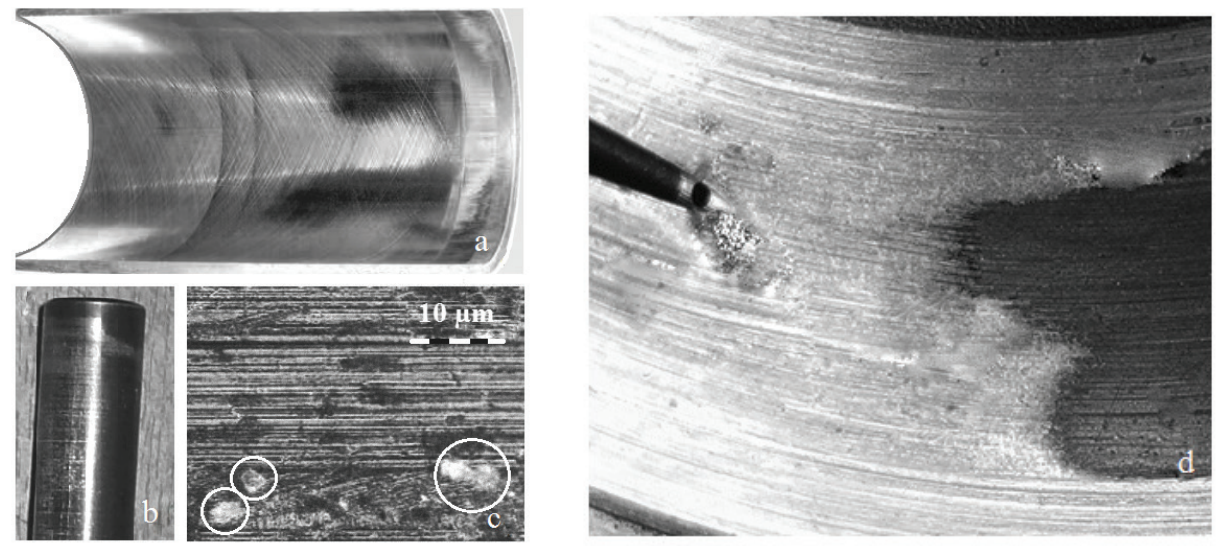

Figure 5. Photos of damage in the plunger pump

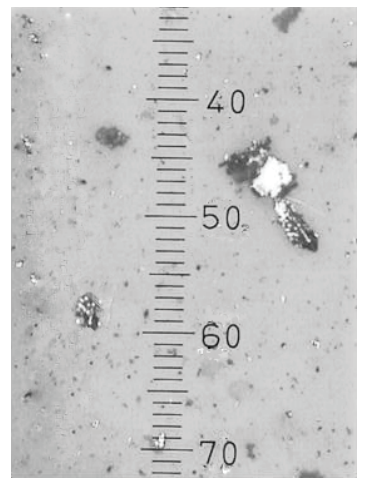

Figure 6. The metal particles after wear of the rubbing parts of the pump

plunger and the cylinder block when working on the same pollutant also explained by the different ratios of hardness between the materials of their surface and the abrasive particles of the pollutant.

During operation of the pump on the working fluid contaminated with abrasive particles, there is an intense wear of the steel cylinder block. Wear products are highly dispersed particles with a size of 1 micron or less. The presence of these particles causes to darken the working fluid (Figure 6). Also in the sample of waste fluid taken after two hours of pump operation (when contaminated with particles of $20 \mu \mathrm{m}$ ), in addition to particles of electrocorundum, there are particles of metallic origin a size from 3 to $10 \mu \mathrm{m}$ (Figure 6). Thus, the total concentration of particles over time in the pump increases.

\section{Conclusions}

The problem of contamination of the working fluid of aircraft with mechanical impurities is currently relevant. As shown by aviation security reports, in recent years there have been accidents associated with the unsatisfactory state of the working fluid. They entail the failure of the aircraft's hydraulic systems. The article pays attention to the influence of mechanical impurities on the relative volume flow rate of the plunger pump and the wear of the rubbing parts. As experiments have shown: with an increase in the size of particles of a pollutant the relative volumetric flow rate of pumps decreases and the intensity of wear of parts increases accordingly. With an increase in the concentration of solid particles with a size of $3 \mu \mathrm{m}$ from 25 to $150 \mathrm{mg} / \mathrm{l}$, the wear rate also increases.

Thus, to improve the performance of hydraulic plunger pumps, it is necessary first of all to increase the wear resistance of their rubbing parts. This will ensure their performance in a wide range of external factors.

In this direction, it is worthwhile to further investigate the effect of the hardness of the contaminant and the discharge pressure of the pump on the wear process.

\section{References}

Boldyrev, S. V., \& Budarova, O. P. (2016). Experimental study of wear of model friction pairs lubricated with contaminated oil. Journal of Friction and Wear, 37(4), 446-451. https://doi.org/10.3103/S1068366616040036

Hong, Y. S., \& Doh, Y. H. (2004). Analysis on the friction losses of a bent-axis type hydraulic piston pump. KSME International Journal, 18(9), 1668. https://doi.org/10.1007/BF02990382

Kovalev, M. A. (2009). Proactive maintenance of hydrosystems on the basis of the analysis of parameters of particles of contamination of hydraulic fluid. Vestnik of Samara University Aerospace and Mechanical Engineering, 19(3), 89-96.

Labunets, V. F., Tit V. A., \& Dmitrenko, A. V. (2010). Prichinyi poteri trudosposobnosti truschihsya detaley aksialno-plunzhernyih gidravlicheskih nasosov. Problemi tertya ta znoshuvannya, (53), 120-127. (in Russian).

National Bureau on Investigation of Aviation Incidents and Incidents with Civil Aircraft. (2015). ANALIZ podii, shcho stalysia pid chas obsluhovuvannia povitrianykh suden na zemli $v$ period $z 2013$ po 2015 rik (in Ukrainian). Retrieved from http://www.nbaai.gov.ua/uploads/pdf/Analysis_PPS.pdf

Wang, X., Lin, S., Wang, S., He, S., \& Zhang, C. (2016). Remaining useful life prediction based on the Wiener process for an aviation axial piston pump. Chinese Journal of Aeronautics, 29(3), 779-788. https://doi.org/10.1016/j.cja.2015.12.020

The West-Siberian Interregional Territorial Department of Air Transport of Federal Air Transport Agency. (2015). Analiz sostoyaniya bezopasnosti poletov $v$ aviapredpriyatiyah i ekspluatantah, podvedomstvennyih ZS MTU Rosaviatsii, v 2014 godu 
Novosibirsk 2015 - C. 110 (in Russian). Retrieved from http:// www.sibfana.ru/files/Analiz_\%202015.pdf

The West-Siberian Interregional Territorial Department of Air Transport of Federal Air Transport Agency. (2016). Analiz sostoyaniya bezopasnosti poletov $v$ aviapredpriyatiyah i ekspluatantah, podvedomstvennyih ZS MTU Rosaviatsii, v 2015 godu Novosibirsk 2016 - C. 73 (in Russian). Retrieved from http:// www.sibfana.ru/files/Analiz_2016(1).pdf
The West-Siberian Interregional Territorial Department of Air Transport of Federal Air Transport Agency. (2017). Analiz sostoyaniya bezopasnosti poletov $v$ aviapredpriyatiyah i ekspluatantah, podvedomstvennyih ZS MTU Rosaviatsii, $v 2016$ godu Novosibirsk 2017 - C. 102 (in Russian). Retrieved from http:// www.sibfana.ru/files/Analiz_2017.pdf 